\title{
Review Article \\ Critically Reflexive Theory: A Proposal for Nursing Education
}

\author{
Jayne Josephsen \\ Boise State University, 1910 University Drive, Boise, ID 83725, USA \\ Correspondence should be addressed to Jayne Josephsen; jaynejosephsen@boisestate.edu \\ Received 17 April 2014; Revised 12 July 2014; Accepted 16 July 2014; Published 24 July 2014 \\ Academic Editor: Allyson Lipp
}

Copyright (C) 2014 Jayne Josephsen. This is an open access article distributed under the Creative Commons Attribution License, which permits unrestricted use, distribution, and reproduction in any medium, provided the original work is properly cited.

\begin{abstract}
Nursing is a discipline in transition. As the complexity and acuity of patients increase, nurses are taking on a more comprehensive role in health care leadership and patient outcomes. As the discipline has evolved so has the curricular framework of nursing educational programs, moving from being based on a specific nursing theory, to a general metaparadigm, to the current focus on meeting curricular content standards developed by national accrediting agencies. When considering the skills needed to fully engage in critical thinking and patient advocacy there may be room for an additional curricular focus: that of metacognitive development based on critical theory and constructivism. The empowerment of students via metacognitive and self-evaluative practices also supports the critical theory pedagogy. If graduating nurses are presented with a cohesive and comprehensive curriculum that meets the need for competent and critically reflexive nurses the discipline of nursing can continue to expand in function and voice. The use of metacognition, constructivism, competency, and critical pedagogies in a unified and broad curricular framework allows for the development of these essential skills in contemporary nursing practice. This paper presents this innovative curricular framework that embodies these various teaching and learning perspectives.
\end{abstract}

\section{Introduction}

Nursing is a discipline in transition. As the complexity and acuity of patients increase, nurses are taking on a more comprehensive role in health care leadership and patient outcomes. As the discipline has evolved so has the curricular framework of nursing educational programs, moving from being based on a specific nursing theory, to a general metaparadigm, to the current focus on meeting curricular content standards developed by national accrediting agencies. In the 1970s there was a call from accrediting agencies and nursing education for each nursing program to choose a specific nursing theory as their conceptual framework for curriculum development, such as Orem's self-care deficit theory. This was found to be inadequate to meet curricular needs, as specific nursing theories mainly focus upon health issues rather than being a comprehensive curricular theory [1].

Nursing education next moved to utilizing a metaparadigm conceptual framework to focus curricular development upon. In this model the metaparadigm of nursing including concepts of person, environment, health, and nursing was employed to communicate the holistic view of the human experience related to the discipline of nursing. Yet this model was found incomplete as well, as it was so generalized it could be applied to a multitude of health care disciplines [2]. Currently, nursing education programs are utilizing national accrediting agency curricular standards, such as the American Association of Colleges of Nursing (AACN) standards, to organize and develop their curriculum. These standards are focused upon curricular content such as professionalism and professional values and baccalaureate generalist nursing practice competencies [3].

Although these national standards do include a focus on values such as professionalism, continuing education, and use of evidence-based practice, the standards tend to be focused on general roles and actions of the professional registered nurse $(\mathrm{RN})$. For example, the generalist baccalaureate $\mathrm{RN}$ is to be able to take on the role of "provider of care, designer/ manager/coordinator of care, and member of a profession" [3, page 8]. Essential to these roles is the need for the RN to be able to critically think, to provide sound clinical judgment, and to have the lens of patient advocacy when providing care. The AACN indicates, in the standards, that the development of these skills is to be culminated in a clinical immersion experience that provides the student with the opportunity to develop these clinical reasoning and evaluation skills [3]. The 
focus then of the AACN accreditation standards is that of competency development related to the discipline of nursing, with skills such as clinical judgment developing somewhat spontaneously with clinical experiences. This is appropriate to an extent, but when considering the skills needed to fully engage in critical thinking and patient advocacy there may be room for an additional curricular focus: that of metacognitive development based on critical theory and constructivism.

It can be argued that the focus on solely competency based curricular theory, that is enmeshed in the rational and behavioristic approaches to knowledge development and integration, has led to a curricular focus in nursing education that ignores the essential aspects of self-awareness and reflexivity in knowledge formation [4]. Yet, thought and mind cannot be separated from the various aspects of society and noetic forces, in this case, nursing curriculum. As Marcuse (as cited in [5]) stated, the critical theory approach desires to bring "to consciousness potentialities that have emerged within the maturing historical situation" (page 158). This brings to question whether curricular theory that is developed in a social framework that supports the focus on facts and competencies, taken out of the context of the relationship of the subjective and objective sphere, promotes development of critical reflection and student potential.

Horkheimer (as cited in [6]) suggested that, for a person to develop their view of reality, insight was needed related to their personal life. This concept of insight is foundational to metacognition. The ability to participate in metacognition, or to think about one's own thoughts and emotions, links the present to the past, to provide a view for the future and to construct meaning of events [7]. Metacognitive practice in learning is an active event in which links are made between the past (prior knowledge), the present (current context), and the future (building upon new knowledge). Thus, it would appear that metacognitive ability is foundational for participation in critically reflexive curricular theory development as well as development of students who are able to participate in critical thinking avenues and knowledge construction and deconstruction [8].

\section{Theoretical Framework}

There are several definitions of metacognition, but for the purposes of applying the concept to curricular theory, metacognition is viewed as a three-part construct that includes self-knowledge, self-evaluation, and applicable knowledge $[9,10]$. It has been shown that the lack of ability to participate in self-evaluative practice can lead to lower literacy abilities and that teaching students metacognitive skills can assist them in transferring the ability to self-evaluate throughout their lives in a variety of settings [10, 11]. Use of self-evaluative practices puts the power back upon the student to direct and think critically about their learning [12]. The empowerment of students via metacognitive and selfevaluative practices also supports the critical theory pedagogy, which embraces the postmodernist concept of autonomy [13].

Currently, graduating nurses are faced with entering a complex and rapidly changing health care environment in which they are required to work more autonomously [14]. There is a demand for self-evaluative and autonomous learners in the discipline of nursing due to this need for nurses to be able to view situations from a variety of perspectives and to translate their past, present, and future knowledge into effective health care interventions. Therefore, nursing curriculum has been challenged to embrace the need for a critically reflexive curriculum, rather than one that is grounded in subject based learning and behavioristic paradigms [15].

Critical theory in conjunction with metacognition offers nursing curriculum a theoretical framework that meets many needs of nursing education, in particular the need to develop critically reflexive students that are able to engage in the professional $\mathrm{RN}$ role that includes ethical activities such as advocacy for social justice and health care equity. Critical reflexivity is dependent upon the student being able to connect internally with their biases and assumptions that often direct decision-making and nursing care. Without this awareness, relationships with our patients and colleagues are often "hidden" as there is little awareness of the symbolic and real meaning of the relationships [16].

Furthermore, use of critical theory as a curricular framework to promote the development of metacognitive abilities and relationship with our patients and colleagues also offers a lens in which the rich history of the discipline of nursing can be integrated into the curriculum as well. Nursing curriculum cannot be devoid of historical foundations, even with the emphasis on evidence-based practice that is currently employed. These historical foundations have created the nursing educational structure that is present today and without understanding of their purpose and value there is likely little critical analysis or awareness of our existing nursing educational structures and their development or future application [16].

Nursing curriculum is also often based upon adult learning concepts as the audience being "taught" is in the higher education setting. Constructivist principles are used largely in this educational setting. Constructivism is based upon the concept that learning occurs "when we construct and deconstruct knowledge..." [17, page 17]. This ability to deconstruct knowledge is found in the capacity to participate in metacognitive/self-evaluative practice. Constructivist theory also involves the curriculum in a critical pedagogy, as the student is engaged in use of applicable knowledge, linking new knowledge to past experiences and then connecting the gained knowledge and/or insight to future nursing practice. Learning occurs as the student internalizes and then reconstructs their reality based upon knowledge gained, modified, or changed [18]. The ability of the student to transfer their knowledge to other contexts and to future practice is imperative for sound clinical judgment and reasoning and is an advantage of integrating metacognition into the curriculum.

The increasing focus from accrediting agencies on competency attainment warrants examination of further integration of metacognition into the curriculum [19]. The purpose of the competency emphasis has been to produce students that meet national nursing standards and recommendations, but the difficulty lies in the varied definitions of competency and how this is to be measured. Another issue of the overall 
focus on competency attainment is that it can create the perception that the nurse is an employee that provides "vocational skills," rather than a professional with the ability to apply technical skills to a variety of situations appropriately and creatively, based upon sound clinical judgment, reasoning, and application of theory and evidence-based practice [20].

One approach to competency based curriculum that has attempted to address the deficits of the singularly competency focused curriculum is the second-generation competency based approach. In this type of curriculum, competency is viewed as a "know-how" that is founded in the combining and engagement of current knowledge, skills, attitudes, and resources and applying them to a specific situation [21]. This is an improvement upon the sort of checklist approach of historical competency based education and may provide the groundwork of metacognitive development. But the framework appears to be incomplete in metacognitive enhancement, as relevance and applicability of competency attainment to future learning and nursing practice is not explicitly addressed. If metacognition is to be fully employed a curricular focus on this ability is required. The ability for students to develop and cultivate self-evaluative and selfreflective skills in which the student can participate in selfdirected learning to address competency deficits as well as an awareness and analysis of their individual thought processes and learning would be foundational to this focus. As it is currently, the second-generation competency based curriculum approach addresses some metacognitive components but may be inconsistently and unpredictably applied.

With these theoretical and conceptual constructs in mind, it may be warranted to develop a nursing curricular theory that employs several theories in a cohesive manner, rather than focusing nursing curriculum on a particular nursing theory or a solely competency based curriculum. The theoretical basis of critical theory, metacognition, constructivism, and competency based curriculum each have a significant role in the development of well-rounded RNs who can meet the demands of contemporary nursing practice. It is a collaborative relationship between the student nurse/RN, curricular theory, and nursing practice. Through these reciprocal relationships the graduating student/ $\mathrm{RN}$ can contribute to the discipline of nursing and society at large through incorporating the lens of each of these theories into their internal knowledge and meaning processes (see Appendix A for critically reflexive theoretical framework with incorporation of various constructs and sample effects on nursing practice and discipline).

\section{Application}

Benner posits a developmental paradigm concerning nursing skill development moving from novice to expert. The novice nurse is one whose skills are limited and they view the world of nursing practice in a "black and white" fashion, fraught with inflexibility in decision-making. This could be identified as the person with limited metacognitive abilities, who is unaware of their learning needs, has limited ability to participate in self-evaluation, and makes few links from past knowledge and present context to future nursing practice. Alternately, the expert is the nurse who possesses a large intuitive ability that they can apply regularly and seamlessly to the present context and anticipates future nursing practice needs [22]. This word intuitive identifies the ability of the expert nurse to look within and reflect upon their abilities and the resources at hand and make a suitable decision. This is an exemplar of the nurse using and internalizing metacognitive abilities into their nursing practice.

Typically, Benner's novice to expert model is viewed from the perspective of the graduate nurse, newly out of school, to the twenty-year veteran nurse. Indeed, Benner has identified that it takes five or more years for the novice nurse to reach expert ability and that some will never reach expert status [22]. Mills (as cited in [23]) suggests that intuition and knowledge are gained via experience and this leads to critical thinking and professional judgment. If some nurses never reach expert status this brings to question the role experience only plays in the development of intuitive expert practice. Is this gap in ability because the novice nurse requires the experience time gives, or is it because we have ill-prepared our graduate nurses for the demands of critically reflexive practice?

Metacognitive ability has been linked to clinical reasoning skills. Throughout clinical reasoning there is "an interaction among the individual's cognition, the subject matter, and the context of the situation where the thinking occurs" (Fowler as cited in [23, page 179]). This statement supports the use of a critical pedagogy in nursing curricula, as it identifies the need to acknowledge the interaction between the past, present, and future in knowledge development. Reflexivity or reflective practice abilities are essential to student nurse transition to practice. Reflection is at the center of metacognition and the development of sound clinical judgment skills. If clinical judgment is presented as a linear, logical organization of facts only, then the thinking process is halted at the end of the continuum and knowledge gained may not be linked to future nursing practice.

Accrediting agencies have called nursing education to provide a curriculum that produces graduates with critical and reflective thinking skills. Nurse educators have endeavored to provide this through concept definitions and creation of measures of critical thinking ability such as the WatsonGlaser Critical Thinking Appraisal. Yet, these measures do not identify use of metacognitive skills, only the potential ability of the student to engage in critical thinking. Critical thinking in nursing education is often seen as a linear approach related to the nursing process, involving a rational view of the situation, rather than identifying self-reflective practice and knowledge of the individuals thinking process [24]. Thus, although nursing education embraces the notion of metacognitive practice and reflexivity, the curriculum is often left with a more behavioristic version of learning and thinking. Barriers to integration of metacognitive practices in the curriculum have been identified as student resistance, lack of time, content overload, institutional barriers, lack of faculty knowledge and/or self-efficacy on the concept, and faculty resistance to pedagogical changes [24].

Mezirow's (as cited in [24]) framework of reflective practice proposes that there are three levels of reflection 
development including absence of reflection, awareness of bias and assessment of decisions, and assessment for further learning and additional perspectives. Often, in nursing education the student is left at the second stage, where the focus is on how personal bias and/or assumptions have affected decisions and then evaluation of the decision. There are few times that the student is required to reflect upon what further learning they may need and what additional world views they may need to become aware of, in order to meet the needs of their patients or to make sense of the reality of nursing practice.

Proust (as cited in [25]) postulates that there are two levels of metacognitive ability, one utilizing the emotional reaction (e.g., intuition) and the second level using reasoning. In this view, use of metacognitive processes allows the student to interpret the context in a corrective fashion based upon their conceptual and factual knowledge, as well as their emotional reactions. This view integrates the use of emotional or nonanalytical processes, metacognition, and the fact oriented clinical decision-making model. This model is supported, as there is a social aspect to metacognitive practices since individual cognition is influenced by social context and experience [26].

When developing the nursing curriculum then, it is essential to integrate all of these components into the coursework and learning process so that the student can take these skills with them into the workplace and promote lifelong learning and building of individual potential. The faculty cannot assume the student will automatically engage in metacognition. In fact, research has shown that these essential metacognitive skills are best introduced within the instructional setting, in order that the student has an opportunity to develop the skills [27, 28]. Metacognitive prompting through question or word stimulus can be used as an instructional adjunctive in nursing education and has been shown to enhance student self-evaluation of comprehension and greater decision-making abilities [29].

Lifelong learning is an internally motivated and enacted outcome of full application of metacognition to the graduate nurses professional development, and thus it has to be a somewhat self-regulated activity. The foundation of selfregulation is metacognitive capacity, reflective strategies, and an understanding of the social, personal, and historical influences upon learning [14]. Self-regulatory ability embodies the critical pedagogy and the potential for self-efficacy.

Furthermore, the ability to coregulate, or to create, meaning in a dynamic process with a multidisciplinary team is essential in the nursing setting. The graduating nurse needs to have the metacognitive awareness to self-regulate as well as an awareness of the other members of the health care team in order to provide quality patient care. For the graduating nurse to engage in this part of the professional nursing role it is vital that they are able to take on various perspectives and engage in a variety of communication techniques, social cognition, and construction and deconstruction of knowledge. The ability to engage successfully in these professional nurse role components requires the individual ability to participate in metacognitive practice [26].

Merriam and Caffarella state that "Metacognition is often viewed as the highest level of mental activity and is especially needed for complex problem solving" [30, page 206]. As the health care setting becomes more complicated, nurses are required to participate in complex problem solving on a daily basis. The ability to engage in clinical judgment and critical thinking is essential to problem solving in this setting, just as metacognitive practice is essential to become an expert nurse who participates in reflective nursing practice. Critical theory supports the connection of the noetic, emotional, and creative knowledge on the individual and societal level as an avenue to address the inherent injustice in our social systems. Pinar suggests that "Busywork may distract us from the facts we face, but serious educational work-academic study-can reconstruct the reality we experience" [31, page 136].

This concept can be translated to our nursing educational systems as well. If educators are not promoting the development of metacognitive capacity in our nursing students, rather focusing on content or behavioristic concepts and skills alone, the student's long-term professional practice needs are not being met. As ideally the professional nurse is able to make connections between all aspects of knowledge, they will be able to identify what they know, what goals for learning they may have, and what they envision their future nursing practice to be, connecting the past, present, and future. Nursing educators ought to examine traditional curriculum with a critical eye and consider the relevance for the traditional content laden, behavioristic focus and if this curricular design is meeting the needs of our graduate nurses and the discipline of nursing as a whole.

Introduction of metacognitive practice and skills throughout nursing curriculum ideally will offer a more holistic view of the students personal nursing practice as well as the discipline of nursing. With the graduating nurses grounded in metacognitive capacity delivered through the nursing curriculum the use of applicable knowledge, selfknowledge, and self-evaluation will be introduced into the health care setting on a personal, organizational, and professional level. Through this engagement in individual and discipline development we can address critical theory and work towards social justice, which is a basic tenet of nursing ethics [32]. Moreover, with the introduction of constructivist concepts such as knowledge construction and deconstruction and a foundation on competency attainment, critically reflexive nurses who provide quality patient care and contribute to the discipline of nursing and the health care system at large can be produced (see Appendix B for sample application of critically reflexive curricular theory to an AACN competency).

\section{Discussion}

There are many factors in determining appropriateness of curricular frameworks and application of these constructs to nursing education. Ultimately, nursing educators are given the responsibility to educate and produce nurses who are able to meet the challenges of current nursing practice as well as meet the demands of the discipline's future. Although there is a need for focus on competency and factual knowledge in nursing curriculum, without a comprehensive curricular framework that includes integration of metacognitive skills, 


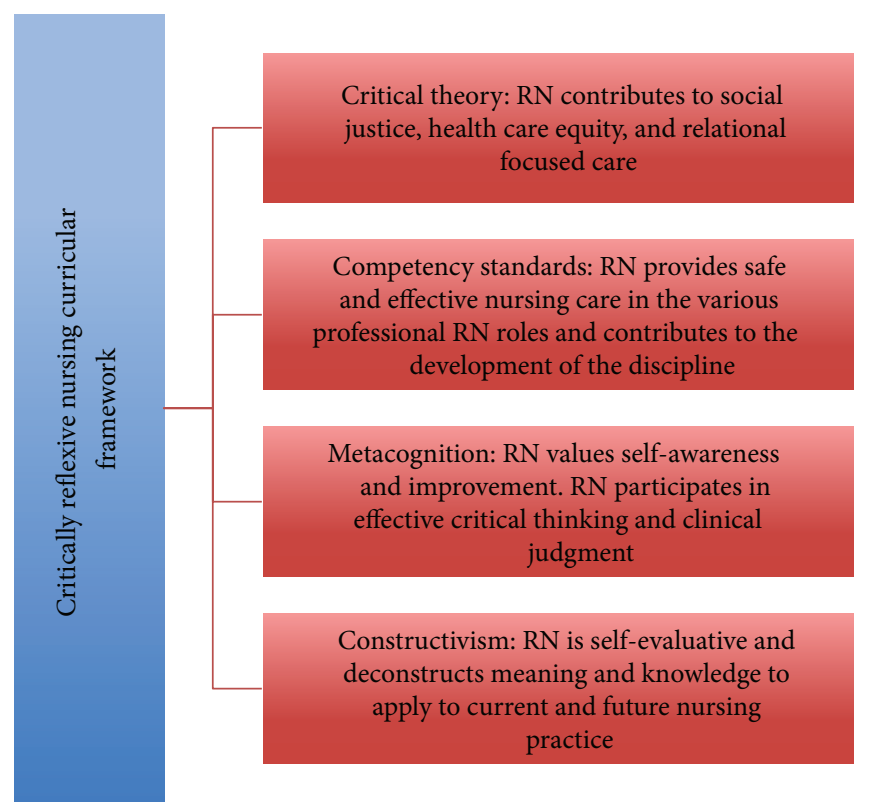

Figure 1

constructivist frameworks, and critical theory tenets, graduating nursing students will likely not have developed the internal critically reflexive skills and knowledge to positively impact the future of nursing.

If we are relying on experience to be the teacher of these skills, we are inadequately preparing our students, as without the framework to become a critically reflexive practitioner introduced to them early on in their careers they may not be able to integrate the benefit of experience fully. Thus, as nursing educators we are left with the challenge to prepare our students not only with nursing skills and knowledge but also with the internal skills of self-evaluation, reflexivity, awareness of thinking and decision-making processes, and instilling of the values of the discipline which include social justice and health care equity. These are considerable requisites of nursing education, yet there are theoretical frameworks available to meet these curricular demands. The theoretical framework proposed in this paper is one that may be able to meet these demands and assist nursing educators in designing curriculum that meets the present needs of our graduating students and the future of nursing.

This paper presents an introduction to a theoretical framework that will require vetting and research for applicability to a variety of nursing educational settings. Implications for research may include introduction of critical theory pedagogy into courses related to professional concepts and leadership. Examination of metacognitive skills and tools application may be appropriate to be introduced and researched in skills, health assessment, and simulation based courses. Constructivist pedagogy can be applied throughout the nursing program, with research to ascertain whether these principles are assisting students to construct and deconstruct knowledge. Lastly, examination of the curricular theoretical framework and its efficacy in producing critical reflexive graduating students can be a focus of research.
If graduating nurses are presented with a cohesive and comprehensive curriculum that meets the need for competent and critically reflexive nurses the discipline of nursing can continue to expand in function and voice. The use of metacognition, constructivism, competency, and critical pedagogies in a unified and broad curricular framework allows for the development of these essential skills in contemporary nursing practice. Just as nursing students are required to participate in critically reflective practice for their individual development and quality patient care outcomes, faculty too are obliged to examine the traditional rational and behavioristic focus of nursing educational curricula and reflect upon whether it is adequately preparing our nursing students for the future of nursing.

\section{Appendices}

\section{A. Critically Reflexive Theoretical Framework with Incorporation of Various Constructs and Sample Effects on Nursing Practice}

See Figure 1.

\section{B. Sample Application of Critically Reflexive Curricular Theory to an AACN Competency}

See Figure 2.

\section{Critically Reflexive Theory Sample Objectives Related to} Leadership Competency

(i) The student will reflect upon biases and values related to end-of-life care and identify how these might affect the quality of patient care and the patient's safety. 


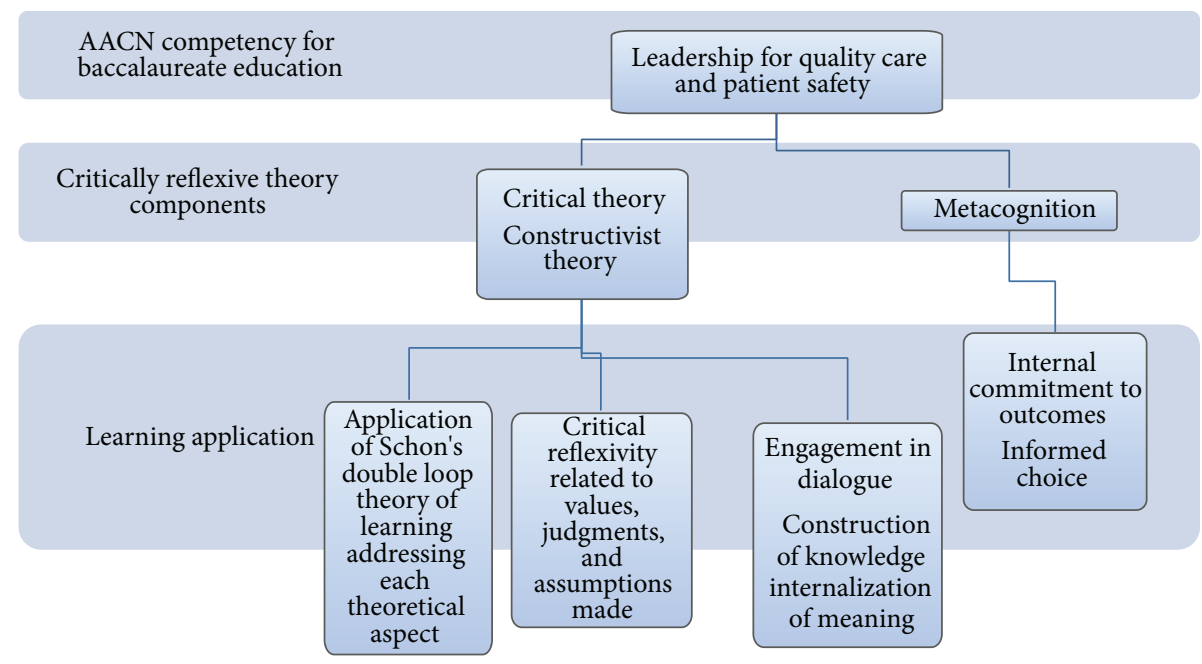

Figure 2

(ii) The student will deconstruct prior knowledge and apply it contextually and through dialogue with the interprofessional team.

(iii) The student will identify strategies to address knowledge or skill deficits related to sterile procedure.

(iv) The student will predict resources needed and patient response to care provided and reflect upon and identify assumptions made in the process.

(v) The student will identify quality improvement techniques that match their learning style and strengths.

(vi) The student will identify improvement strategies that address any self-identified weaknesses concerning patient safety.

(vii) The student will create a learning portfolio identifying how they have met the leadership competency. Portfolio will include reflection on values and assumption related to the competency, what the competency means to them individually for their future nursing practice, and exploration of how they will address issues of commitment to outcomes and strategies for informed choice.

(See $[3,33]$.

\section{Conflict of Interests}

The author declares that there is no conflict of interests regarding the publication of this paper.

\section{References}

[1] V. A. Berbiglia, "The self-care deficit nursing theory as a curriculum conceptual framework in baccalaureate education," Nursing Science Quarterly, vol. 24, no. 2, pp. 137-145, 2011.

[2] P. Webber, "A curriculum framework for nursing," Journal of Nursing Education, vol. 41, no. 1, pp. 15-24, 2002.

[3] American Association of Colleges (AACN), The Essentials of Baccalaureate Education for Professional Nursing Practice,
American Association of Colleges, Washington, DC, USA, 2008.

[4] M. Horkheimer, Critical Theory: Selected Essays, Continuum International Publication Group, London, UK, 1975.

[5] C. Fuchs, "Critical theory of information, communication, media, and technology," 2013, http://www.heathwoodpress .com/critical-theory-of-information-communication-media-technology/.

[6] D. Martindale, The Nature and Types of Sociological Theory, Waveland Press, Project Heights, Ill, USA, 2nd edition, 1981.

[7] K. D. Buck and P. H. Lysaker, "Addressing metacognitive capacity in the psychotherapy for Schizophrenia: a case study," Clinical Case Studies, vol. 8, no. 6, pp. 463-472, 2009.

[8] L. Chartier, "Use of metacognition in developing diagnostic reasoning skills of novice nurses," International Journal of Nursing Terminologies and Classifications, vol. 12, no. 2, pp. 55-60, 2001.

[9] B. Kim, H. Park, and Y. Baek, "Not just fun, but serious strategies: using meta-cognitive strategies in game-based learning," Computers and Education, vol. 52, no. 4, pp. 800-810, 2009.

[10] P. J. Worrell, "Metacognition: implications for instruction in nursing education," The Journal of Nursing Education, vol. 29, no. 4, pp. 170-175, 1990.

[11] K. J. Aceti and Y. Wang, "The teaching and learning of multimeaning words within a metacognitively based curriculum," The American Annals of the Deaf, vol. 155, no. 2, pp. 118-123, 2010.

[12] M. E. Fonteyn and M. Cahill, "The use of clinical logs to improve nursing students'metacognition: a pilot study," Journal of Advanced Nursing, vol. 28, no. 1, pp. 149-154, 1998.

[13] D. Scott, Critical Essays on Major Curriculum Theorists, Routledge, New York, NY, USA, 2008.

[14] R. Kuiper, "Enhancing metacognition through the reflective use of self-regulated learning strategies," Journal of continuing education in nursing, vol. 33, no. 2, pp. 78-87, 2002.

[15] A. F. Nilsson and C. Silén, “You have to know why': the influence of different curricula on nursing students' perceptions of nursing," Scandinavian Journal of Educational Research, vol. 54, no. 6, pp. 631-642, 2010.

[16] M. Apple, Ideology and Curriculum, RoutledgeFalmer, New York, NY, USA, 3rd edition, 2009. 
[17] K. Iverson and D. Colky, "Scenario-based e-learning design," Performance Improvement, vol. 43, no. 1, pp. 16-22, 2004.

[18] P. Doolittle and W. Camp, "Constructivism: the career and technical education perspective [electronic version]," Journal of Vocational and Technical Education, vol. 16, no. 1, 1999.

[19] M. O. Forbes and M. T. Hickey, "Curriculum reform in baccalaureate nursing education: review of the literature," International Journal of Nursing Education Scholarship, vol. 6, no. 1, article 27, 2009.

[20] C. Windsor, C. Douglas, and T. Harvey, "Nursing and competencies-a natural fit: the politics of skill/competency formation in nursing," Nursing Inquiry, vol. 19, no. 3, pp. 213-222, 2012.

[21] J. Goudreau, J. Pepin, S. Dubois, L. Boyer, C. Larue, and A. Legault, "A second generation of the competency-based approach to nursing education," International Journal of Nursing Education Scholarship, vol. 6, no. 1, 2009.

[22] L. Carlson, N. Crawford, and S. Contrades, "Nursing student novice to expert-Benner's research applied to education," The Journal of Nursing Education, vol. 28, no. 4, pp. 188-190, 1989.

[23] M. Banning, "Clinical reasoning and its application to nursing: concepts and research studies," Nurse Education in Practice, vol. 8, no. 3, pp. 177-183, 2008.

[24] R. A. Kuiper and D. J. Pesut, "Promoting cognitive and metacognitive reflective reasoning skills in nursing practice: selfregulated learning theory," Journal of Advanced Nursing, vol. 45, no. 4, pp. 381-391, 2004.

[25] J. A. Marcum, "An integrated model of clinical reasoning: dualprocess theory of cognition and metacognition," Journal of Evaluation in Clinical Practice, vol. 18, no. 5, pp. 954-961, 2012.

[26] S. P. Lajoie and J. Lu, "Supporting collaboration with technology: does shared cognition lead to co-regulation in medicine?" Metacognition and Learning, vol. 7, no. 1, pp. 45-62, 2012.

[27] M. Huba and J. Freed, Learner-Centered Assessment on College Campuses: Shifting the Focus from Teaching to Learning, Allyn and Bacon, Boston, Mass, USA, 2000.

[28] M. E. Jones, P. D. Antonenko, and C. M. Greenwood, "The impact of collaborative and individualized student response system strategies on learner motivation, metacognition, and knowledge transfer," Journal of Computer Assisted Learning, vol. 28, no. 5, pp. 477-487, 2012.

[29] L. Fiorella, J. J. Vogel-Walcutt, and S. Fiore, "Differential impact of two types of metacognitive prompting provided during simulation-based training," Computers in Human Behavior, vol. 28, no. 2, pp. 696-702, 2012.

[30] S. Merriam and R. Caffarella, Learning in Adulthood: A Comprehensive Guide, Jossey-Bass, San Francisco, Calif, USA, 2nd edition, 1999.

[31] W. Pinar, What is Curriculum Theory? Routledge, New York, NY, USA, 2nd edition, 2012.

[32] American Nurses Association, "Code of ethics for nurses," 2001, http://www.nursingworld.org/codeofethics.

[33] J. Mezirow, "A critical theory of adult learning and education," Adult Education Quarterly, vol. 32, no. 1, pp. 3-24, 1981. 


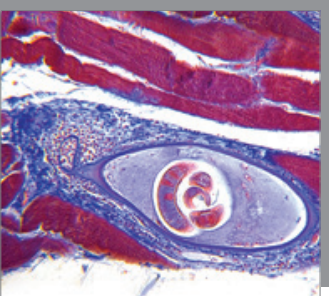

Gastroenterology

Research and Practice
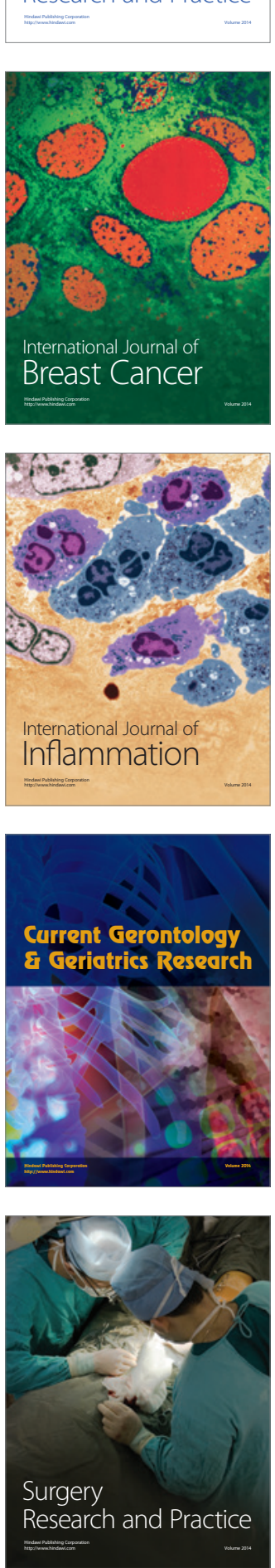

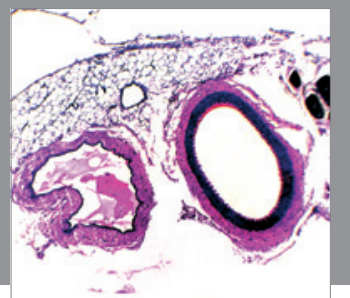

International Journal of Hypertension
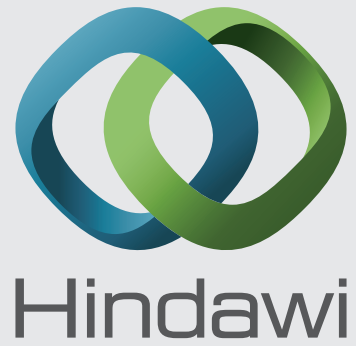

Submit your manuscripts at http://www.hindawi.com
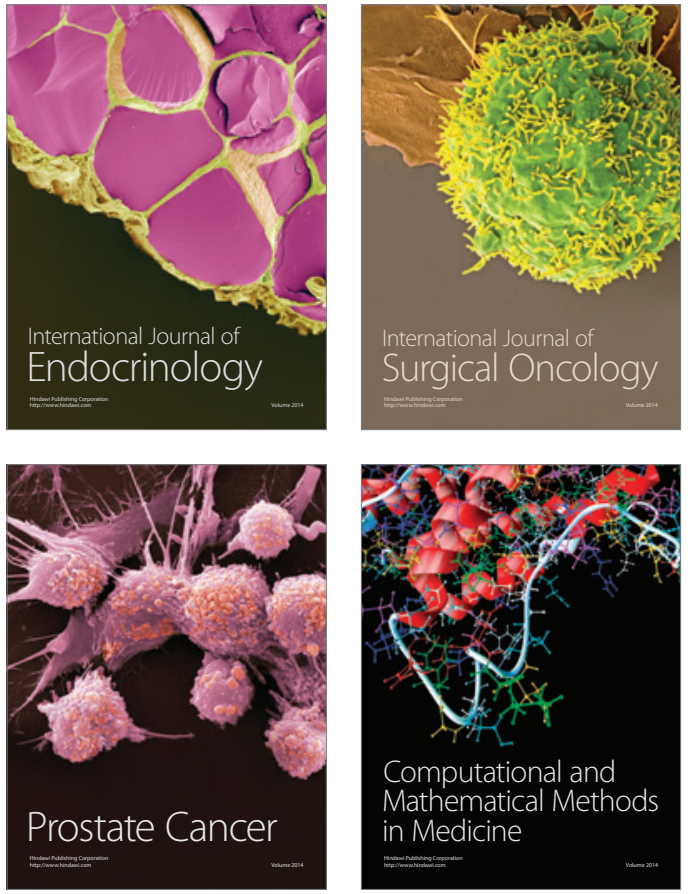
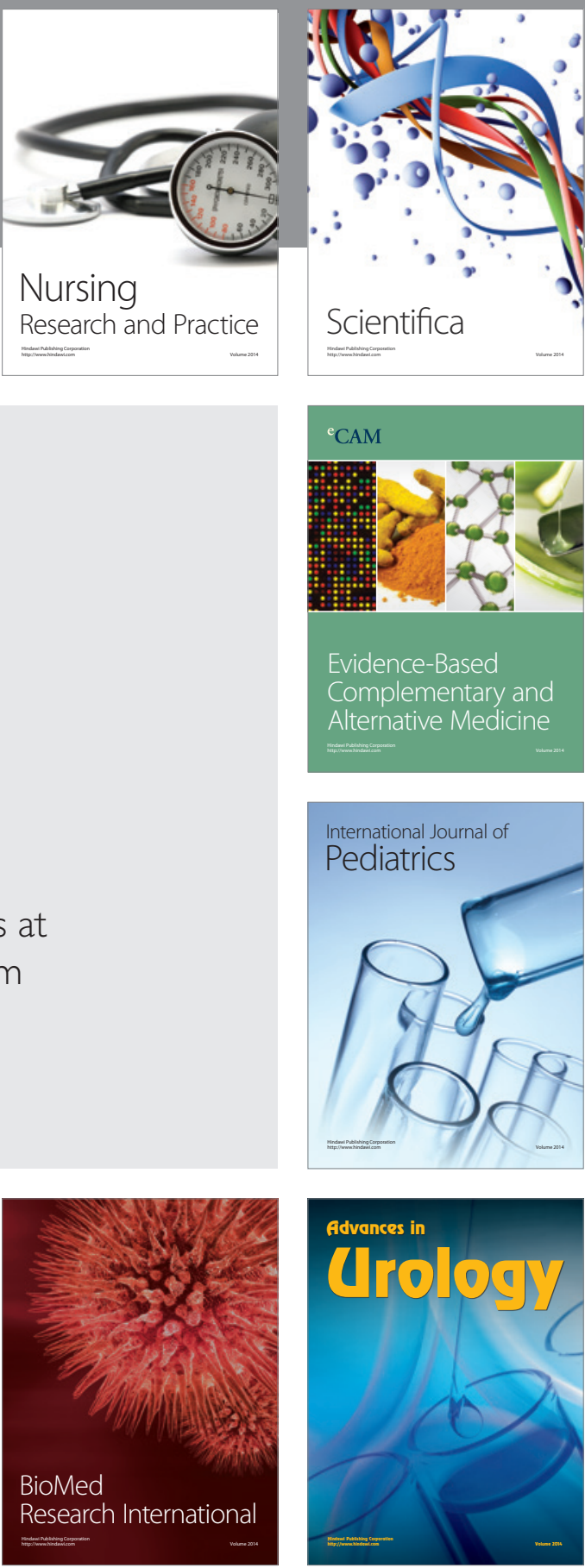

Nursing

Research and Practice

Scientifica

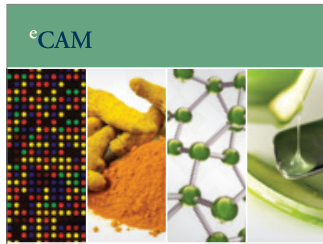

Evidence-Based

Complementary and Alternative Medicine
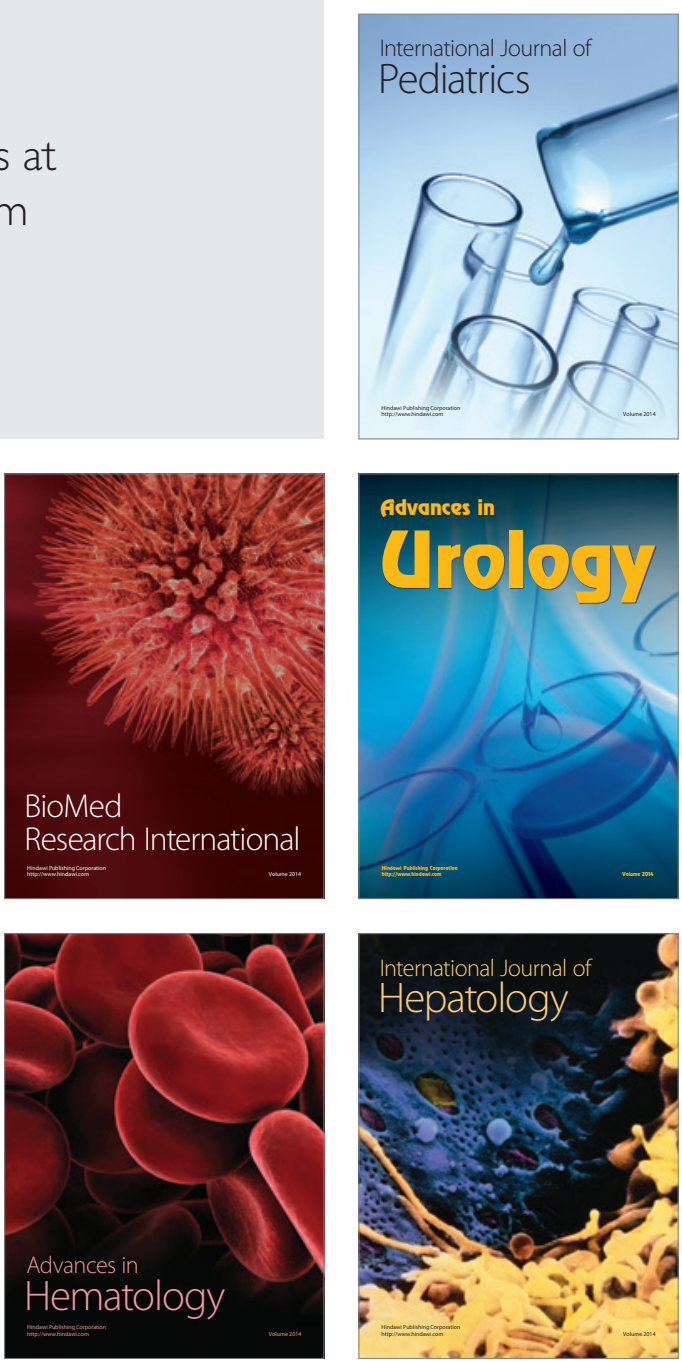